Yüzüncü Y1 Üniversitesi
Tarim Bilimleri Dergisi

Araştırma Makalesi (Research Article)

\title{
Yerel Pazı (Beta vulgaris L. var. cicla) Genotiplerinin Agronomik Özelliklerinin Belirlenmesi**
}

\author{
Emre DEMIREL ${ }^{1}$, M. Kadri BOZOKALFA ${ }^{* 2}$ \\ ${ }^{1,2}$ Ege Üniversitesi Ziraat Fakültesi Bahçe Bitkileri Bölümü, 35100 Bornova, İzmir, Türkiye \\ ${ }^{1} \mathrm{https}$ //orcid.org/0000-0001-6762-1483 ${ }^{2} \mathrm{https} / / /$ orcid.org/0000-0002-5607-2308 \\ *Sorumlu yazar e-posta: mehmet.kadri.bozokalfa@ege.edu.tr
}

\section{Makale Bilgileri}

Geliş: 15.04 .2021

Kabul: 18.11.2021

Online Yayınlanma: 15.12 .2021

DOI: $10.29133 /$ yyutbd.916691

\section{Anahtar Kelimeler}

Bitki genetik kaynakları, Ön 1slah çalışmaları, Seleksiyon, Varyabilite.
Öz: Pazı (Beta vulgaris L. var. cicla) yetiştiriciliği kolay, zengin besin içeriğine sahip, yaprakları sebze olarak değerlendirilen bir türdür. İklim ve toprak isteği yönünden fazla seçici olmaması, hastalık ve zararlılara dirençli genlere sahip olması ve içerdiği önemli besin bileşikleri nedeniyle ıslah programları açısından değerli bir bitkidir. Ülkemizde çok geniş alanlarda yetiştiriciliği yapılmamasına karşın üretimde farklı bölgelere yayılmış yerel populasyonlar yoğun olarak kullanılmaktadır. Çalışmada, Türkiye'nin farklı bölgelerinden toplanmış 3 yerli ve 1 yabancı orijinli çeşit olmak üzere toplam 53 pazı genotipi agronomik özellikler bakımından değerlendirilmiştir. Elde edilen sonuçlar bitkisel materyali oluşturan gen havuzundaki genotipler arasında yaprağın agronomik özellikleri yanında; bitki başına yaprak sayısı, yaprak ağırlığı, yaprak alanı gibi verim komponentleri yönünden de yüksek düzeyde varyasyonun varlığını ortaya koymaktadır. İncelenen yerel genotipler arasında özellikle üretici ve tüketici tercihlerinin odak noktasında yer alan, yüksek yaprak alanı, kısa yaprak sapı, koyu yeşil yaprak rengi ve verim komponentleri yönünden mevcut ticari çeşitlerden çok daha üstün genotipler belirlenmiştir. Pazı koleksiyonunda agronomik özellikler yönünden yüksek çeşitliliğin görülmesi, bu materyalin 1slahta kullanılarak yeni pazı çeşitlerinin geliştirilebilme potansiyeline katkı sağlamakta ve gen kaynaklarının korunmasının önemine vurgu yapmaktadır. Ayrıca elde edilen sonuçlar, istenilen agronomik özelliklere sahip ve yüksek verimli pazı çeşitlerinin geliştirilmesi için ıslah programlarına önemli bilgiler sunmaktadır.

\section{Determination of Agronomic Properties of Local Swiss Chard (Beta vulgaris L. var. cicla.) Genotypes}

\section{Article Info}

Received: 15.04 .2021

Accepted: 18.11.2021

Online Published: 15.12.2021

DOI: $10.29133 /$ yyutbd.916691

\section{Keywords}

Plant genetic resources, Pre-breeding studies, Selection,

Variability.
Abstract: Swiss chard (Beta vulgaris L. var. cicla) is a vegetable that is easy to grow, has rich nutritional values, and its leaves are used. It is a valuable plant for breeding programs due to its low selectivity in terms of climate and soil properties, resistance genes to diseases and pests contains the important nutriencompounds. Although it is not cultivated in very large areas in Turkey, local populations spread over different regions are used intensively for production. In this study, 53 Swiss chard genotypes including three local cultivars and one foreign genotype were examined for agronomic properties. The research revealed a high level of agronomic diversity in terms of evaluated agronomic leaf traits particularly yield components such as the number of leaves per plant, leaf weight, and leaf area among the genotypes. In addition, compared to the commercial cultivars, there are superior genotypes were determined among the population for consumer and farmer preferred traits for large leaf area, short petiole, dark green leaf color, and yield. Identification of the agronomic diversity among the present Swiss chard collection may contribute to knowledge on valuable scientific information in terms of breeding new Swiss chard varieties and the importance of conservation of 
genetic material. In addition, the obtained results contribute to the use of this collection in breeding programs aiming to develop high-yielding Swiss chard varieties with desired agronomic characteristics.

**Bu makale Emre DEMIREL'in yüksek lisans tez çalışmasının sonuçlarından düzenlenmişstir.

\section{Giriş}

M.Ö. 300'den günümüze yabani pazı köklerinin halk tarafindan ilaç olarak kullanıldığı ve pazı yetiştiriciliği yapıldığ 1 bilinmektedir. Linne tarafindan 1753 yılında ilk defa bir sebze türü olarak sinıflandırılan (Lange ve ark., 1999) pazının anavatanı; genel olarak Akdeniz ülkeleri olarak belirtilmesine karşın, Kafkas ülkeleri, Anadolu ve Yakındoğu ülkelerinin batı kesimleri de orijini içinde bulunmaktadır. Frese ve ark. (2001) Kuzey Avrupa'da yetiştirilen pancarın Fırat-Dicle havzasında ilk kültüre alındığını bildirmiştir. Fakat Cheng ve ark. (2011) ilk kültüre alınma merkezi olarak Avrupa ve Akdeniz bölgesi olduğunu belirtmiştir. Oyen (2004) yabani pancarın 9. yüzyılda Mezopotamya'da yaprakları için yetiştirildiği görüşünü desteklemiştir. Sun (1994), kültüre alınan pazının Çin'de 5. yüzyıldan beri var olduğunu ve Avrupa'da antik zamanlardan beri yetiştirilmekte olduğunu bildirmiştir. Pazının (Beta vulgaris L. var. cicla) yer aldığı "Chenopodiaceae" familyası dünya üzerinde tanımlanmış 103 cins ve 1400 kadar tür içerirken, Türkiye'de 33 cinse ait 129 tür bulunmaktadır (Gürsul, 2015; Yıldırımlı, 2003). Beta cinsi hem yabani hem de kültüre alınmış formları içeren dört bölümden oluşur (Letschert ve ark., 1994). Bunlar: beta, corollinae, nanae ve procumbentes'dir (Shen ve ark., 1998). Dünyada yetiştiriciliği yapılan formları; şeker pancarı, yem pancarı ve pazıyı kapsayan Beta vulgaris'i içerir (Shen ve ark., 1998). Beta cinsinin yerel dağılımı esas olarak Avrupa'da iken, nanae kategorisi Yunanistan'da yayılım gösterir ve procumbentes Kanarya Adaları'nda bulunmaktadır. Türkiye'de beta ve corollinae daha geniş coğrafi dağılıma sahiptir (Frese ve ark., 2001).

Günümüzde pazı küresel olarak, Kuzey Hindistan, Güney Amerika, Amerika Birleşik Devletleri ve Akdeniz Ülkeleri'nde yetiştirilmektedir (Bozokalfa ve ark., 2011). Almanya'da 19. yüzyılda pancar bitkisinde yürütülen ıslah çalışmalarının ardından pazı bitkisinin ticari önemi artmıştır (Ninfali ve Angelino, 2013).

Pazı, yabani ve kültüre alınmış Beta türleri arasında nispeten değerli bir türdür. Çünkü genetik yapısı itibarıyla hastalık ve zararlılara karşı direnç gösteren genleri sayesinde ıslah için değerli bir kaynaktır (Goldman ve Navazio, 2003). Pazının (Beta vulgaris L. subsp. vulgaris) B. procumbens ve $B$. webbiana ile ayrı ayrı çaprazlanmasıyla elde edilen melezleri, şeker pancarında verimli hibritler üretilmesinde köprü görevi görmektedir (Gaskill, 1954; Goldman ve Navazio, 2003; Bozokalfa ve ark., 2016).

Arazi açmaları, yerli çeşitlerin yerine sslah edilmiş ticari çeşitlerin kullanılması, doğal afetler, şehirleşme ve endüstrileşme, üretmeden doğadan sökerek tüketme gibi nedenlerle mevcut bitkisel çeşitlilik hızla azalmakta ve hatta kaybolmaktadır. Bu nedenlerden dolayı, XIX. yüzyılın başlarında mevcut tehlikenin bilincine varan pek çok ülkede bitki genetik kaynaklarının çeşitlilik düzeyleri tespit edilmeye ve muhafaza altına alınmaya başlanmıştır (Balkaya ve Yanmaz, 2001). Pazı gen kaynaklarının tanımlanması, sağlık açısından önemli bileşiklerin geliştirilmesi ve hedeflenen agronomik özelliklere ulaşılması için yürütülecek yeni 1slah programlarına temel oluşturacak bilimsel bilgiye katkı sağlayabilir. Ayrıca istenen karakterlerin eldesi için şeker pancarı ıslah programlarında değerli bir gen kaynağı olarak kabul edilebilir (Baranski ve ark., 2001). Gen kaynaklarının tanımlanması, genotipler arasındaki taksonomik ilişkilerinin belirlenmesi, bitki genetik kaynaklarının değerlendirilmesi, 1slahçılara genetik materyal sağlamak yönünden önemlidir.

Uzun yıllardan beri yetiştirilen yerel populasyonların en büyük avantajı, yetiştirildiği bölgenin koşullarını adapte olması ve bu özelliğini koruyabilmesidir. Bu bağlamda farklı bölgelere ve ekolojilere adapte olmuş yerel populasyonların ıslah programlarındaki önemi artmaktadır. Dünya'da kültürü yapılan birçok türde yerel populasyonlar toplanarak ıslah materyali olarak kullanılmaktadır. Son yıllarda pazı 1slahında farklı sap rengine sahip (turuncu, mor, kırmızı), erken hasat olgunluğuna gelen, dik yaprak geliştiren ve gevrek yapılı çeşitler geliştirilmesine yönelik çalışmalar yürütülmektedir. Diğer yandan biotik ve abiotik stress koşullarına dayanıklılık kazandırılması için Beta cinsine giren türler arasında yapılan melezlemelerde başarı oranının yüksek olması, bu yönüyle pazı genotiplerinin gen kaynağı olarak değerini artırmaktadır. 
Bu çalışmada, Türkiye'nin farklı lokasyonlarından toplanmış yerel populasyonlardan elde edilen pazı genotiplerinin agronomik özelliklerinin belirlenmesi ve ıslah programlarında doğrudan veya genitör olarak değerlendirilebilecek umutvar genotiplerin belirlenmesi amaçlanmıştır.

\section{Materyal ve Yöntem}

\subsection{Materyal}

Araştırmada bitkisel materyal olarak Türkiye'nin farklı bölgelerinden toplanmış 49 yerel pazı genotipi ile birlikte karşılaştırma yapılabilmek amacıyla 1 yabancı ve 3 yerli çeşit olmak üzere toplam 53 pazı genotipi kullanılmıştır (Çizelge 1). Çalışmada kullanılan yerel pazı genotiplerine ait tohumlar Ege Üniversitesi Ziraat Fakültesi Bahçe Bitkileri Ana Bilim Dalından temin edilmiştir.

Çizelge 1. Genotiplerin aksesyon numarası/isimleri, toplandığı yer ve ülke

\begin{tabular}{|c|c|c|c|c|c|}
\hline Genotip & Toplandığı yer & Ülke & Genotip & Toplandığı yer & Ülke \\
\hline TR 30741 & Gaziantep & Türkiye & TR 55689 & Trabzon & Türkiye \\
\hline TR 35012 & Çanakkale & Türkiye & TR 55756 & Rize & Türkiye \\
\hline TR 35065 & Bursa & Türkiye & TR 55767 & Rize & Türkiye \\
\hline TR 35137 & Tokat & Türkiye & TR 55778 & Rize & Türkiye \\
\hline TR 35164 & Kayseri & Türkiye & TR 55787 & Rize & Türkiye \\
\hline TR 35180 & Sivas & Türkiye & TR 55800 & Rize & Türkiye \\
\hline TR 35278 & Şanlıurfa & Türkiye & TR 55821 & Rize & Türkiye \\
\hline TR 35821 & Mardin & Türkiye & TR 55832 & Artvin & Türkiye \\
\hline TR 35289 & Mardin & Türkiye & TR 55848 & Artvin & Türkiye \\
\hline TR 35316 & Hakkari & Türkiye & TR 55866 & Artvin & Türkiye \\
\hline TR 35354 & Muğla & Türkiye & TR 55879 & Artvin & Türkiye \\
\hline TR 35355 & Muğla & Türkiye & TR 55889 & Artvin & Türkiye \\
\hline TR 35393 & Hatay & Türkiye & TR 55931 & Rize & Türkiye \\
\hline TR 40459 & Siirt & Türkiye & TR 55983 & Trabzon & Türkiye \\
\hline TR 43621 & Sakarya & Türkiye & TR 55993 & Trabzon & Türkiye \\
\hline TR 46354 & Kayseri & Türkiye & TR 55999 & Trabzon & Türkiye \\
\hline TR 51154 & Hatay & Türkiye & TR 56010 & Trabzon & Türkiye \\
\hline TR 51160 & Adana & Türkiye & TR 56017 & Giresun & Türkiye \\
\hline TR 51169 & Mersin & Türkiye & TR 56046 & Ordu & Türkiye \\
\hline TR 51170 & Mersin & Türkiye & TR 71077 & Kayseri & Türkiye \\
\hline TR 51194 & Muğla & Türkiye & TR 73437 & Türkiye & Türkiye \\
\hline TR 51199 & İzmir & Türkiye & TR 73438 & Türkiye & Türkiye \\
\hline TR 52424 & Erzurum & Türkiye & Yerli Çeşit & Pinaper seed & Türkiye \\
\hline TR 52488 & Artvin & Türkiye & Yabanc1 çeşit & Freya & Almanya \\
\hline TR 55632 & Giresun & Türkiye & Zümrüt & İstanbul Tohum & Türkiye \\
\hline TR 55633 & Giresun & Türkiye & Tuna & Balıkesir Tohum & Türkiye \\
\hline TR 55664 & Giresun & Türkiye & & & \\
\hline
\end{tabular}

\subsection{Yöntem}

Araştırma Ege Üniversitesi Ziraat Fakültesi Bahçe Bitkileri Bölümü Uygulama ve Araştırma alanları ve laboratuvarlarında yürütülmüştür. Ege Bölgesi ova koşullarında pazı yetiştiriciliğine uygun olarak 20 Eylül 2017 tarihinde doğrudan toprağa elle tohum ekimleri yapılmış ve deneme sıralarına damla sulama boruları çekilmiştir. Deneme tesadüf blokları deneme desenine uygun olacak şekilde 3 tekerrürlü olarak dizayn edilmiş, sıra aras $70 \mathrm{~cm}$ ve sıra üzeri $30 \mathrm{~cm}$ ekim mesafeleri uygulanmıştır. Tohumlar çimlenip toprak yüzeyine çıktıktan sonra seyreltilerek her ocakta tek bitki kalması sağlanmış ve her parselde 10 bitki olacak şekilde deneme yürütülmüştür.

Bitki gelişme dönemi içerisinde yabancı otlar ile mücadele ve toprağın havalandırılması için 15 Ekim ve 10 Kasım 2017 tarihlerinde elle çapa işlemi yapılmıştır. Tohum ekiminden vejetasyon süresi sonuna kadar tüm kültürel işlemler düzenli olarak yürütülmüştür (Vural ve ark., 2000). Bitki besleme 
amacıyla toprak analiz sonuçlarına uygun olarak $14 \mathrm{~kg} / \mathrm{da}$ Mono Amonyum Fosfat ve $12 \mathrm{~kg} / \mathrm{da}$ Mono Potasyum Fosfat damla sulama yöntemiyle uygulanmıştır (Çizelge 2).

Çizelge 2. Deneme alanı toprağının fiziksel ve kimyasal özellikleri ile makro ve mikro element içerikleri

\begin{tabular}{|c|c|c|c|}
\hline \multicolumn{2}{|c|}{ İncelenen Özellikler } & Birimi & Miktarları \\
\hline \multicolumn{2}{|l|}{$\mathrm{pH}$} & & 7.3 \\
\hline \multicolumn{2}{|c|}{ Elektriksel İletkenlik (EC) } & $\mathrm{mS} \mathrm{cm}^{-1}$ & 0.5 \\
\hline \multicolumn{2}{|c|}{ Kireç $\left(\mathrm{CaCO}_{3}\right)$} & $\%$ & 2.86 \\
\hline \multicolumn{2}{|c|}{ Kum } & $\%$ & 61.5 \\
\hline \multicolumn{2}{|l|}{ Kil } & $\%$ & 19.6 \\
\hline \multicolumn{2}{|c|}{ Mil } & $\%$ & 18.9 \\
\hline \multicolumn{2}{|c|}{ Bünye } & & Kumlu-Tın \\
\hline \multicolumn{2}{|c|}{ Organik Madde } & $\%$ & 1.06 \\
\hline \multicolumn{2}{|c|}{ Toplam Azot (N) } & $\%$ & 0.081 \\
\hline \multirow{9}{*}{ 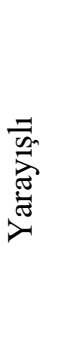 } & Fosfor $(\mathrm{P})$ & $\mathrm{mg} \mathrm{kg}^{-1}$ & 1.6 \\
\hline & Potasyum (K) & $\mathrm{mg} \mathrm{kg}^{-1}$ & 398 \\
\hline & Kalsiyum (Ca) & $\mathrm{mg} \mathrm{kg}^{-1}$ & 377 \\
\hline & Magnezyum (Mg) & $\mathrm{mg} \mathrm{kg}^{-1}$ & 450 \\
\hline & Sodyum (Na) & $\mathrm{mg} \mathrm{kg}^{-1}$ & 19 \\
\hline & $\operatorname{Demir}(\mathrm{Fe})$ & $\mathrm{mg} \mathrm{kg}^{-1}$ & 14 \\
\hline & $\operatorname{Bakır}(\mathrm{Cu})$ & $\mathrm{mg} \mathrm{kg}^{-1}$ & 9 \\
\hline & Çinko (Zn) & $\mathrm{mg} \mathrm{kg}^{-1}$ & 5 \\
\hline & Mangan (Mn) & $\mathrm{mg} \mathrm{kg}^{-1}$ & 59 \\
\hline
\end{tabular}

\section{3. İncelenen agronomik özellikler ve verim parametreleri}

Agronomik özelliklerin belirlenmesi için her parselde hasat olgunluğuna ulaşmış 10 farklı bitkiden yapraklar elle hasat edilmiş ve bunlar arasından tesadüfen seçilen 10 adet yaprak örneğinde aşağıda belirtilen özellikler incelenmiştir. Lamina uzunluğu $(\mathrm{cm})$ : sapın bitişinden laminanın ucuna kadar cetvel ile ölçüm yapılmıştır. Lamina genişliği $(\mathrm{cm})$ : laminanın en geniş kısmından cetvel ile ölçüm yapılmıştır. Ortalama yaprak ağırlığı $(\mathrm{g})$ : bir parselden hasat edilen yaprakların toplam ağırlığı tartılmış hasat edilen yaprak sayısına bölünerek hesaplanmıştır. Yaprak rengi $\left(\mathrm{L}^{*}\right.$, Hue, Kroma): Her bir genotipin yapraklarının rengi Minolta-CR 300 renk ölçer ile belirlenmiş, buradan elde edilen a ve b değerleri kullanılarak: kroma (renk doygunluğu $)=\sqrt{ } \mathrm{a}^{2}+\mathrm{b}^{2}$ ve hue (renk niteliği) $=\tan ^{-1}[\mathrm{~b} / \mathrm{a}]$ değerleri hesaplanmıştır. Yaprak alanı $\left(\mathrm{cm}^{2}\right)$ : her parselde hasat olgunluğuna ulaşmış beş farklı bitkiden 1'er adet yaprak örneği hasat edildikten hemen sonra tarayıcıda "Leaf Scan" bilgisayar programı ile taranarak yaprak alanı hesaplanmıştır. Yaprak sapı çapı $(\mathrm{cm})$, yaprak sapının en geniş kısımdan dijital kumpas ile ölçülmüştür. Yaprak sapı kalınlığı (mm), yaprak sapının en kalın kısmından dijital kumpas ile ölçülmüştür. Bitki başına yaprak sayısı (adet/bitki), bir parselden elde edilen toplam yaprak sayısının hasat yapılan bitki sayısına bölünmesi ile hesaplanmıştır. Verim $(\mathrm{kg} / \mathrm{da})$, bitki başına elde edilen verimin bir dekar alanda yer alan bitki sayısı ile çarpılmasıyla hesaplanmıştır.

\subsection{Verilerin istatistiki değerlendirilmesi}

Tarla ve laboratuvar çalışmalarından elde edilen agronomik özelliklere ait veri seti kullanılarak varyans analizi yapılmış ve genotipler arasındaki farklar SPSS (v22.0) istatistik programında Tukey's$\mathrm{b}$ testi ile belirlenmiştir.

\section{Bulgular}

\subsection{Yaprağın agronomik özellikleri}

Taze yaprakları sebze olarak tüketilen pazı genotiplerine ait ölçülen ve hesaplanan agronomik özellikler ele alındığında, incelenen genotipler arasında tüm özellikler yönünden istatistiksel önem düzeyinde farklılıklar olduğu gözlenmiştir (Çizelge 3). 
Çizelge 3. Pazı genotiplerinin yaprakların agronomik ve renk özellikleri

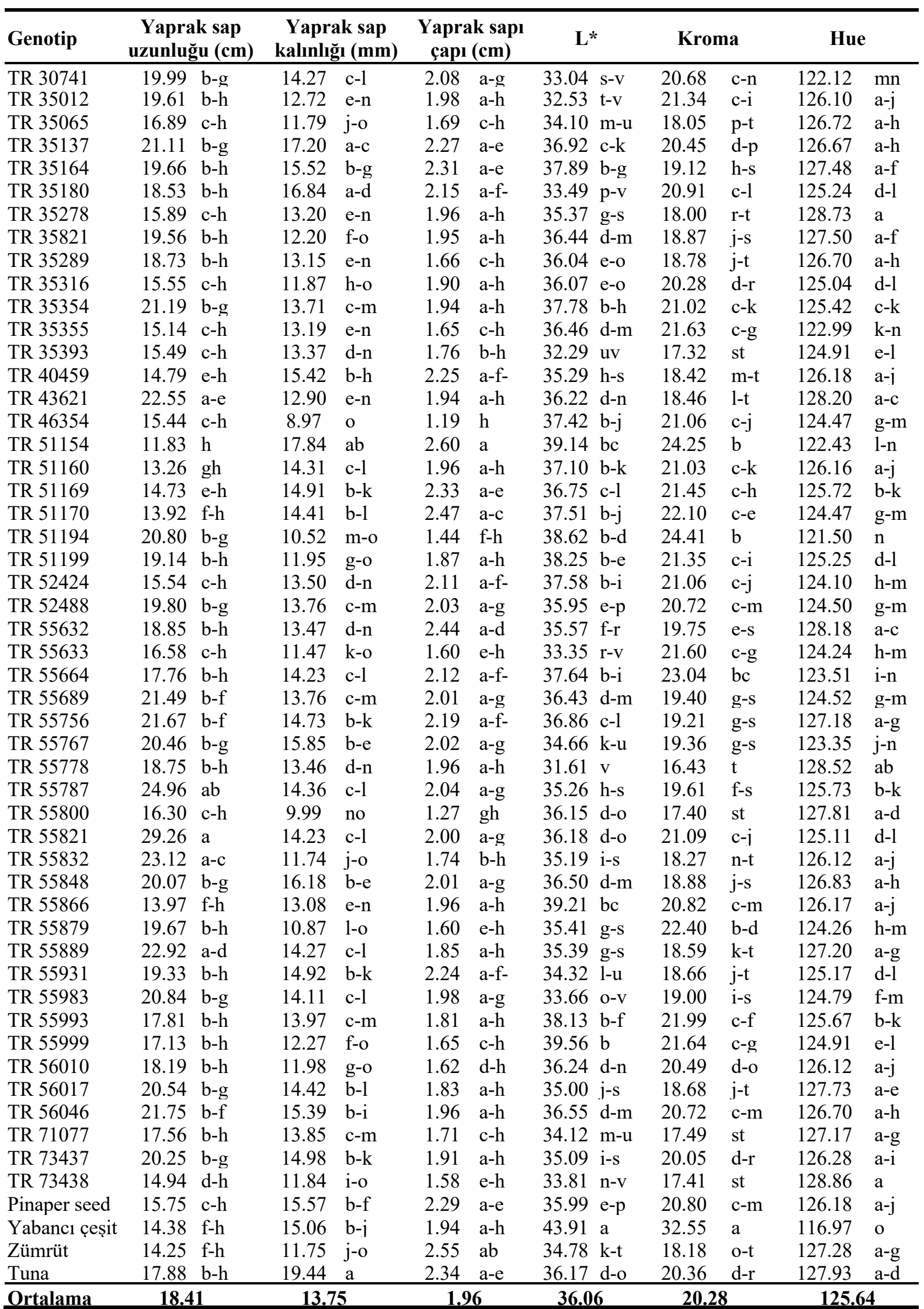

${ }^{\mathrm{a}-\mathrm{z}}$ Genotipler arasındaki farkın istatistiki düzeyde $(P<0.05)$ önemli olduğunu ifade eder. 
Genotiplerin yaprak sapı uzunluk değerleri incelendiğinde en uzun yaprak sapı değeri $29.26 \mathrm{~cm}$ ile TR 55821 genotipinde bulunurken en kısa yaprak sapı değeri $11.83 \mathrm{~cm}$ ile TR 51154 genotipinde ölçülmüştür (Çizelge 3). Yaprak sap kalınlıkları incelendiğinde en kalın yaprak sapı $19.44 \mathrm{~mm}$ ile Tuna genotipinde ölçülmüş en ince yaprak sapı ise $8.97 \mathrm{~mm}$ ile TR 46354 genotipinde ölçülmüştür. Yaprak sapı çapı incelendiğinde ise genotipler arasında en yüksek değer $2.60 \mathrm{~cm}$ ile TR 51154 genotipinde ölçülürken en düşük değer $1.19 \mathrm{~cm}$ ile TR 46354 genotipinde bulunmuştur.

Yaprağ 1 tüketilen sebze türlerinde tüketiciyi etkileyen kalite parametreleri arasında yaprağın canlı ve türe ait koyu yeşil rengi göstermesi kalite ile ilişkilendirilmektedir. Bu kapsamda incelenen yaprak renk özellikleri arasında istatistiki olarak farklılıklar görülmüş, yaprak parlaklığını ifade eden L* değerleri en yüksek (43.91) yabancı çeşitte ölçülmüss, yerel genotiplerin parlaklık değerleri genel olarak daha düşük seviyede yer almış ve en düşük yaprak $L^{*}$ değeri ise 31.61 ile TR 55778 genotipinde ölçülmüştür. Yaprak renk doygunluğunu ifade eden kroma renk değerleri incelendiğinde hesaplanan kroma değeri geniş bir değer (16.43-32.55) aralığında yer alırken yaprakların soluk yeşilden canlı yeşil renge kadar geniş renk skalasında dağılım gösterdiği hesaplanmıştır. En düşük kroma değeri TR 55778 genotipinden en yüksek kroma ise yabancı çeşitte hesaplanmıştır. İncelenen bir diğer renk parametresi olan yaprak hue değeri yeşil rengin koyuluğunu ifade ederken yüksek hue değerine sahip genotiplerin yapraklarının daha koyu yeşil renge sahip olduğunu göstermektedir. Genotiplerin hue renk değerleri göz önünde bulundurulduğunda en yüksek yaprak hue renk değeri 128.86 ile TR 73438 genotipinde hesaplanmış, en düşük yaprak hue renk değeri ise 116.97 ile yabancı çeşitte belirlenmiştir.

Yaprak alanını oluşturan lamina uzunluğu ve genişliği bakımından yapılan değerlendirmede genotiplerin lamina uzunluğu 22.30-38.30 cm arasında değişkenlik göstermiş en uzun lamina TR 51154 genotipinde, en kısa lamina ise TR 35355 genotipinde ölçülmüştür. Lamina genişliğine bakıldığında ise en yüksek lamina genişliği $21.72 \mathrm{~cm}$ ile TR 55993 genotipinde, en düşük lamina genişliğinin $13.64 \mathrm{~cm}$ ile TR 46354 genotipinde ölçüldügüü belirlenmiştir. Pazıda sebze olarak değerlendirilen kısım büyük oranda laminadır, bu nedenle lamina alanı olarak kabul edilebilecek yaprak alanı değeri önemli bir seleksiyon kriteri olarak karşımıza çıkmaktadır. Yaprak alanı yönünden yüksek düzeyde varyabilite görülürken en geniş yaprak alanı $736.33 \mathrm{~cm}^{2}$ ile TR 35354 genotipinde, en düşük yaprak alanı ise 208.81 $\mathrm{cm}^{2}$ ile TR 46354 genotipinde hesaplanmıştır.

\subsection{Verim ve verim komponentleri}

Pazı 1slahında verim komponentleri arasında ortalama yaprak ağırlığ 1 ve bitki başına yaprak sayısı ilk sırada gelmektedir. Bu yönüyle genotipler incelendiğinde bitki başına en yüksek yaprak sayısının 25.04 adet ile TR 55866 genotipinde olduğu saptanmıştır, bitki başına en düşük yaprak sayısı ise 6.06 adet ile TR 71077 genotipinde bulunmuştur (Çizelge 4). Bitki başına yaprak sayısı bakımından genotipler arasında yüksek varyabilite görülürken benzer durum yaprak ağırlığı değerlerinde de görülmektedir. Yaprak ağırlığı yönünden yapılan değerlendirmede en yüksek yaprak ağırlığının 100.78 $\mathrm{g}$ ile TR 35354 genotipinden, en düşük yaprak ağırlığının ise $26.62 \mathrm{~g}$ ile TR 46354 genotipinden elde edildiği görülmektedir. Pazı ıslahında yaprağın agronomik özellikleri yanında verim önemli bir unsurdur, incelenen genotiplerin verim değerleri oldukça geniş bir aralıkta dağılım göstermiş ve istatistiksel düzeyde farklı1ık belirlenmiştir. En yüksek dekar verimi $7429 \mathrm{~kg} / \mathrm{da}$ ile TR 51170 genotipinden, en düşük verim ise $1422 \mathrm{~kg} / \mathrm{da}$ ile TR 71077 genotipinden sağlandığı tespit edilmiş̧ir (Şekil 1). İncelenen bitkisel materyal arasında en verimli ticari çeşidin Tuna $(4501 \mathrm{~kg} / \mathrm{da})$ olduğu görülmüş yerel genotipler arasında ise çok daha yüksek verim değerine sahip genotiplerin varlığı göze çarpmaktadır. Tarafımızdan elde edilen bulgular değerlendirildiğinde agronomik özelliklere ait verilerin geniş bir aralıkta değişim gösterdiği belirlenmiş, bu varyasyonun temelinde ise genotipler arasında genetik farklılı̆̆ın yer aldığı, ayrıca ekolojik koşulların yaprağın agronomik özellikleri ve buna bağlı verim komponentlerinde farkl1lıklara neden olduğu düşünülmektedir. 
Çizelge 4. Pazı genotiplerinin bazı agronomik özellikleri ve verim komponentleri

\begin{tabular}{|c|c|c|c|c|c|c|c|c|c|c|}
\hline \multirow{2}{*}{$\begin{array}{l}\text { Genotip } \\
\text { TR 30741 }\end{array}$} & \multicolumn{2}{|c|}{$\begin{array}{l}\text { Lamina uzunluğu } \\
(\mathbf{c m})\end{array}$} & \multicolumn{2}{|c|}{$\begin{array}{l}\text { Lamina genişliği } \\
(\mathbf{c m})\end{array}$} & \multicolumn{2}{|c|}{$\begin{array}{c}\text { Yaprak alanı } \\
\left(\mathrm{cm}^{2}\right)\end{array}$} & \multicolumn{2}{|c|}{$\begin{array}{c}\text { Bitki başına yaprak } \\
\text { sayısı (adet) }\end{array}$} & \multicolumn{2}{|c|}{$\begin{array}{c}\text { Ortalama yaprak } \\
\text { ağırlığı (g) }\end{array}$} \\
\hline & 29.28 & $b-e$ & 18.43 & $b-j$ & 281.88 & $f-m$ & 15.22 & $b-h$ & 43.80 & $d-f$ \\
\hline TR 35012 & 27.53 & $\mathrm{c}-\mathrm{e}$ & 20.37 & $a-e$ & 310.13 & $\mathrm{~d}-\mathrm{m}$ & 17.70 & $a-h$ & 48.93 & $b-f$ \\
\hline TR 35065 & 24.95 & de & 17.60 & $\mathrm{~d}-\mathrm{m}$ & 361.52 & $b-i$ & 17.84 & $a-h$ & 51.37 & $b-f$ \\
\hline TR 35137 & 30.10 & $a-e$ & 19.97 & a-g & 332.6 & b-1 & 19.08 & $a-h$ & 53.69 & $b-f$ \\
\hline TR 35164 & 25.99 & $c-e$ & 21.23 & $a b$ & 292.03 & e-m & 12.58 & $\mathrm{~g}-\mathrm{i}$ & 64.17 & b-e \\
\hline TR 35180 & 30.62 & $a-e$ & 19.13 & $a-i$ & 389.89 & b-g & 18.70 & $a-h$ & 57.55 & $b-f$ \\
\hline TR 35278 & 27.31 & c-e & 17.68 & $\mathrm{c}-\mathrm{m}$ & 350.29 & $\mathrm{~b}-\mathrm{k}$ & 10.28 & $h-i$ & 71.04 & $a-d$ \\
\hline TR 35821 & 29.07 & b-e & 14.67 & $\mathrm{~m}-\mathrm{o}$ & 265.34 & $\mathrm{~h}-\mathrm{m}$ & 13.41 & $\mathrm{~d}-\mathrm{i}$ & 60.66 & $b-f$ \\
\hline TR 35289 & 26.53 & $c-e$ & 17.71 & $\mathrm{c}-\mathrm{m}$ & 266.28 & $\mathrm{~h}-\mathrm{m}$ & 17.32 & $a-h$ & 65.97 & b-e \\
\hline TR 35316 & 28.31 & $\mathrm{c}-\mathrm{e}$ & 16.68 & h-n & 327.69 & b-m & 16.15 & $b-h$ & 70.38 & $a-d$ \\
\hline TR 35354 & 26.40 & $\mathrm{c}-\mathrm{e}$ & 18.71 & $a-i$ & 736.33 & $\mathrm{a}$ & 12.67 & $\mathrm{~g}-\mathrm{i}$ & 100.78 & $\mathrm{a}$ \\
\hline TR 35355 & 22.30 & $\mathrm{e}$ & 17.47 & e-m & 329.06 & b-1 & 17.44 & $a-h$ & 65.36 & b-e \\
\hline TR 35393 & 25.83 & c-e & 15.75 & $\mathrm{k}-\mathrm{O}$ & 308.95 & $\mathrm{~d}-\mathrm{m}$ & 12.52 & $g-i$ & 37.92 & $d-f$ \\
\hline TR 40459 & 29.31 & b-e & 20.06 & $a-d$ & 248.3 & $\mathrm{i}-\mathrm{m}$ & 13.27 & $\mathrm{e}-\mathrm{i}$ & 44.33 & $d-f$ \\
\hline TR 43621 & 30.10 & a-e & 17.87 & $c-1$ & 366.84 & $b-i$ & 13.08 & $e-i$ & 53.92 & $b-f$ \\
\hline TR 46354 & 22.67 & $\mathrm{e}$ & 13.64 & o & 208.81 & $\mathrm{~m}$ & 21.33 & $\mathrm{a}-\mathrm{g}$ & 26.62 & $\mathrm{f}$ \\
\hline TR 51154 & 38.30 & $\mathrm{a}$ & 20.77 & $a-d$ & 370.9 & b-h & 19.93 & $\mathrm{a}-\mathrm{g}$ & 81.94 & $a-c$ \\
\hline TR 51160 & 31.27 & $a-e$ & 16.70 & g-n & 308.55 & $\mathrm{~d}-\mathrm{m}$ & 18.02 & $a-h$ & 56.71 & $b-f$ \\
\hline TR 51169 & 31.37 & a-e & 19.78 & $a-h$ & 312.55 & $\mathrm{~d}-\mathrm{m}$ & 16.65 & $a-h$ & 68.63 & $a-d$ \\
\hline TR 51170 & 29.09 & b-e & 18.24 & $\mathrm{~b}-\mathrm{k}$ & 421 & $b-d$ & 21.89 & $a-f$ & 84.63 & $a b$ \\
\hline TR 51194 & 22.97 & $\mathrm{e}$ & 17.81 & $\mathrm{c}-\mathrm{m}$ & 254.04 & $\mathrm{~h}-\mathrm{m}$ & 16.26 & $a-h$ & 51.94 & $b-f$ \\
\hline TR 51199 & 29.14 & b-e & 16.07 & $\mathrm{i}-\mathrm{n}$ & 282.91 & $\mathrm{f}-\mathrm{m}$ & 21.02 & a-g & 37.84 & $d-f$ \\
\hline TR 52424 & 30.77 & $a-e$ & 18.68 & $a-j$ & 308.2 & $\mathrm{~d}-\mathrm{m}$ & 12.48 & $g-\hat{i}$ & 50.74 & $b-f$ \\
\hline TR 52488 & 30.18 & a-e & 19.49 & $a-h$ & 292.35 & e-m & 12.96 & $\mathrm{f}-\mathrm{i}$ & 56.54 & $b-f$ \\
\hline TR 55632 & 29.94 & $a-e$ & 19.10 & $a-i$ & 245.87 & $\mathrm{i}-\mathrm{m}$ & 14.06 & $c-i$ & 46.17 & $c-f$ \\
\hline TR 55633 & 27.84 & c-e & 15.92 & $\mathrm{j}-\mathrm{n}$ & 296.93 & e-m & 16.31 & $a-h$ & 51.27 & $b-f$ \\
\hline TR 55664 & 28.91 & b-e & 19.52 & $a-h$ & 336.92 & b-l & 14.94 & b-h & 56.06 & $b-f$ \\
\hline TR 55689 & 25.77 & $\mathrm{c}-\mathrm{e}$ & 16.84 & $f-m$ & 265.22 & $\mathrm{~h}-\mathrm{m}$ & 14.28 & $c-i$ & 55.88 & $b-f$ \\
\hline TR 55756 & 29.45 & b-e & 18.56 & $a-i$ & 253.75 & $\mathrm{~h}-\mathrm{m}$ & 16.04 & b-h & 51.76 & $b-f$ \\
\hline TR 55767 & 30.14 & a-e & 16.61 & h-n & 344.66 & b-l & 17.02 & $a-h$ & 54.99 & $b-f$ \\
\hline TR 55778 & 32.51 & $a-d$ & 19.03 & $a-i$ & 405.86 & b-e & 18.30 & $a-h$ & 69.50 & $a-d$ \\
\hline TR 55787 & 29.32 & b-e & 19.17 & $a-i$ & 362.11 & $b-i$ & 19.41 & $\mathrm{a}-\mathrm{g}$ & 54.66 & $b-f$ \\
\hline TR 55800 & 23.88 & de & 14.46 & no & 225.09 & $\operatorname{lm}$ & 22.65 & $a-c$ & 45.22 & $d-f$ \\
\hline TR 55821 & 24.11 & $\mathrm{de}$ & 19.68 & $a-h$ & 393.53 & $b-f$ & 23.24 & $a b$ & 56.61 & $b-f$ \\
\hline TR 55832 & 27.70 & c-e & 17.13 & $\mathrm{f}-\mathrm{m}$ & 368.05 & $b-i$ & 23.48 & $\mathrm{ab}$ & 45.44 & $d-f$ \\
\hline TR 55848 & 30.39 & $a-e$ & 16.82 & g-n & 264.06 & $\mathrm{~h}-\mathrm{m}$ & 22.29 & $a-d$ & 61.31 & $b-f$ \\
\hline TR 55866 & 28.80 & b-e & 16.03 & $\mathrm{i}-\mathrm{n}$ & 316.2 & $\mathrm{c}-\mathrm{m}$ & 25.04 & $\mathrm{a}$ & 46.14 & $c-f$ \\
\hline TR 55879 & 28.07 & $\mathrm{c}-\mathrm{e}$ & 16.52 & i-n & 341.32 & b-1 & 17.09 & $a-h$ & 51.40 & $b-f$ \\
\hline TR 55889 & 30.66 & $a-e$ & 20.95 & $a-c$ & 349.53 & $\mathrm{~b}-\mathrm{k}$ & 21.99 & a-e & 58.66 & $b-f$ \\
\hline TR 55931 & 29.44 & b-e & 18.56 & $a-i$ & 346.11 & $\mathrm{~b}-\mathrm{k}$ & 18.17 & $a-h$ & 52.75 & $b-f$ \\
\hline TR 55983 & 29.36 & b-e & 18.91 & $a-j$ & 342.12 & b-l & 12.86 & $g-i$ & 51.12 & $b-f$ \\
\hline TR 55993 & 31.06 & a-e & 21.72 & $\mathrm{a}$ & 432.36 & $\mathrm{bc}$ & 16.71 & $a-h$ & 71.89 & $a-d$ \\
\hline TR 55999 & 26.88 & $c-e$ & 17.66 & $\mathrm{~d}-\mathrm{m}$ & 239.71 & $\mathrm{k}-\mathrm{m}$ & 20.67 & $a-g$ & 45.91 & $d-f$ \\
\hline TR 56010 & 26.63 & $c-e$ & 17.94 & $\mathrm{c}-1$ & 272.09 & $\mathrm{~g}-\mathrm{m}$ & 13.60 & $\mathrm{~d}-\hat{\mathrm{i}}$ & 37.63 & $d-f$ \\
\hline TR 56017 & 30.25 & $a-e$ & 17.27 & e-m & 351.32 & $\mathrm{~b}-\mathrm{k}$ & 16.17 & b-h & 50.70 & $b-f$ \\
\hline TR 56046 & 29.19 & b-e & 20.62 & $a-d$ & 339.68 & b-l & 16.15 & $b-h$ & 51.02 & $b-f$ \\
\hline TR 71077 & 29.19 & b-e & 17.69 & $\mathrm{c}-\mathrm{m}$ & 334.64 & b-1 & 6.06 & $\mathrm{i}$ & 47.98 & $c-f$ \\
\hline TR 73437 & 32.81 & $a-d$ & 19.00 & $a-j$ & 314.13 & $\mathrm{c}-\mathrm{m}$ & 15.62 & b-h & 62.72 & b-e \\
\hline TR 73438 & 25.06 & de & 14.75 & $1-0$ & 317.58 & $\mathrm{c}-\mathrm{m}$ & 19.49 & $\mathrm{a}-\mathrm{g}$ & 31.52 & ef \\
\hline Pinaper seed & 34.44 & $a-c$ & 18.03 & b-1 & 317.58 & $\mathrm{c}-\mathrm{m}$ & 15.31 & $b-h$ & 51.33 & $b-f$ \\
\hline Yabanc1 çeșit & 34.50 & $a-c$ & 20.69 & $a-d$ & 439.87 & $\mathrm{~b}$ & 12.56 & $g-i$ & 61.77 & $b-f$ \\
\hline Zümrüt & 26.85 & $\mathrm{c}-\mathrm{e}$ & 18.53 & $b-i$ & 289.81 & e-m & 13.12 & $\mathrm{e}-\mathrm{i}$ & 60.01 & $b-f$ \\
\hline Tuna & 37.38 & $\mathrm{ab}$ & 19.68 & $a-h$ & 308.84 & $\mathrm{~d}-\mathrm{m}$ & 15.75 & b-h & 60.71 & $b-f$ \\
\hline Ortalama & 28.87 & & 18.1 & & 327.2 & & 16.72 & & 55.61 & \\
\hline
\end{tabular}

${ }^{\mathrm{a}-\mathrm{z}}$ Genotipler arasındaki farkın istatistiki düzeyde $(P<0.05)$ önemli olduğunu ifade eder. 


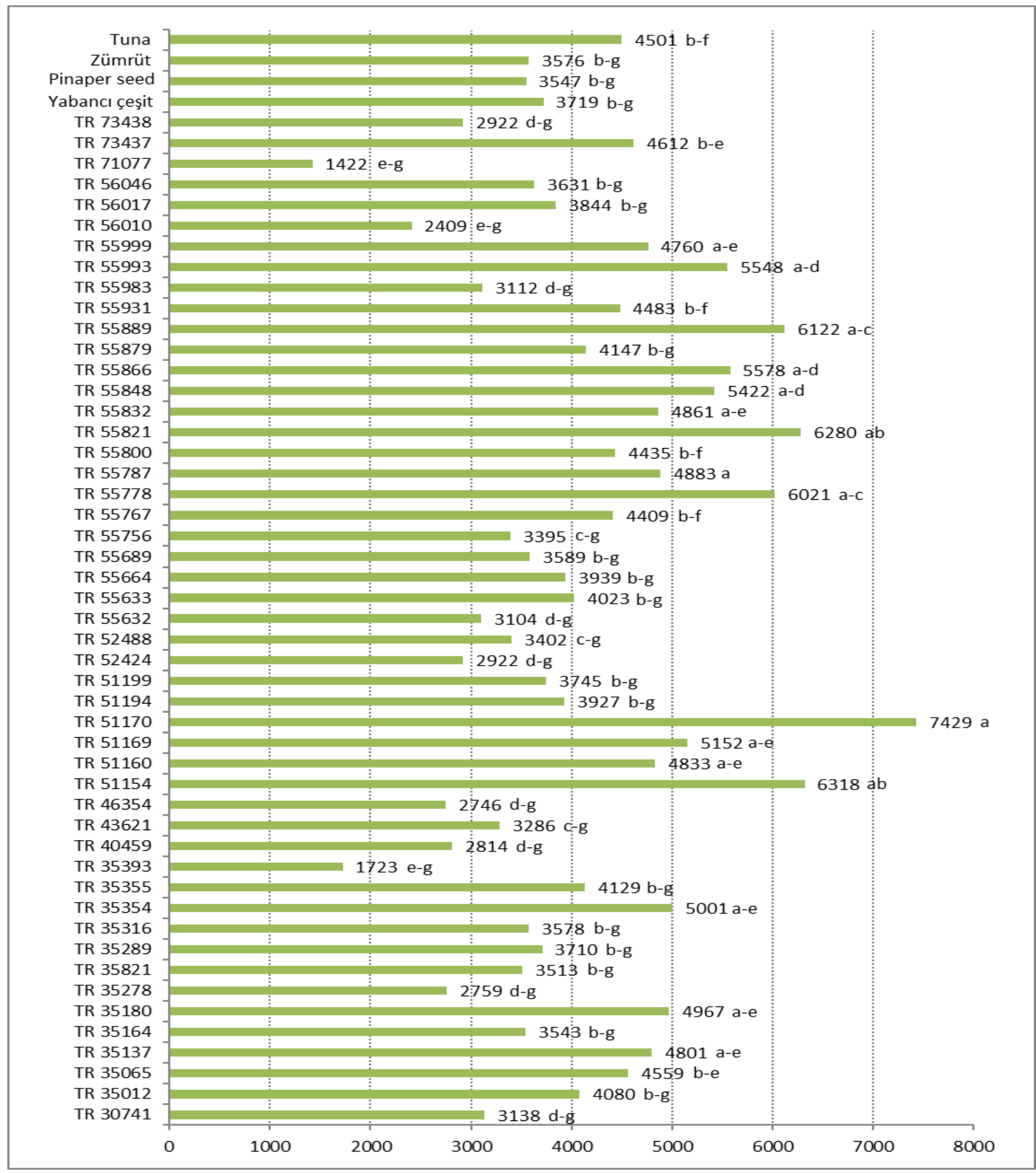

Şekil 1. Pazı genotiplerinin verim değerleri $(\mathrm{kg} / \mathrm{da})$ ve çoklu karşılaştırma testinde yer aldıkları istatistik gruplar.

\section{Tartışma ve Sonuç}

Elde edilen veriler değerlendirildiğinde incelenen bitki özelliklerinde yaprak ağırlığı, yaprak sap1 genişliği, yaprak sap1 kalınlığı, yaprak sap1 uzunluğu, lamina uzunluğu ve lamina genişliği varyasyon gösteren karakterler arasında ilk sıralarda yer almaktadır. Yüksek düzeydeki bu varyasyon 1slah açısından farklı karakterlere sahip çeşitlerin geliştirilmesinde doğrudan veya genitör olarak kullanılmasına olanak sağlamaktadır. Nitekim uzun yıllar süresince üreticiler tarafından tüketim talepleri ve yetiştirildiği bölgenin ekolojik koşullarına uygunluğu göz önünde bulundurularak yapılan seleksiyonlar kültürü yapılan bitki türlerinin çeşitliliğine katkı sağlamaktadır. Bozokalfa ve ark. (2011) pazı gen kaynaklarının çeşitliliği üzerine yaptıkları çalışmada farklı coğrafi konumlardan toplanan pazı örnekleri arasında agromorfolojik özellikler bakımından geniş bir varyabilite olduğunu bildirmektedir. 
Tarafımızdan yapılan çalışmadan elde edilen bulgular yaprak sapı genişliği $(0.89-1.94 \mathrm{~cm})$ ve yaprak sap1 kalınlığı $(0.64-2.22 \mathrm{~cm})$ değerleri, Pokluda ve Koben (2002) tarafından bildirilen petiol genişliği $(1.19-2.60 \mathrm{~cm})$ ve yaprak sapı kalınlığ $1(1.36-3.55 \mathrm{~cm})$ değerleri ile uyum içerisinde yer almıştır. Aynı araştırıcılar bitki ağırlığı, bitki yüksekliği, yaprak sayısı ve verimin çeşitlere göre değiştiğini vurgulamış, pazı genotipleri arasında bitki başına yaprak sayısının 6.7-15.8 adet arasında değiştiğini belirtmişlerdir, tarafimızdan elde edilen bitki başına yaprak sayısı 6.06-25.4 ise bu değerler ile uyum içerisindedir. Genotiplerin yaprak sapı uzunlukları 11.83-29.26 cm arasında değiştiği belirlenmiş ve Eşiyok ve ark. (2011)'nın yaptıkları çalışmadan elde ettiği 5.46-18.28 cm yaprak sap uzunluk değerleri ile uyum içerisinde olduğu görülmüştür.

Pazı 1slahında yaprağın agronomik karakterleri yanında verim özellikleri çeşidin pazar şansını artıran önemli bir unsurdur. Genotiplerin verim değerleri incelendiğinde verim değerinin en yüksek $7429 \mathrm{~kg} / \mathrm{da}$ ile TR 51170 genotipinden, en düşük verimin $1422 \mathrm{~kg} / \mathrm{da}$ ile TR 71077 genotipinden sağlandığı tespit edilmiştir. Pokluda ve Kuben (2002) yaptığı çalışmada pazı genotipleri arasında bitki başına verim değerlerini 161-519 g aralığında olduğunu bildirmiş en düşük verim değerinin $1.6 \mathrm{t} / \mathrm{da}$ en yüksek verim değerinin 5.2 t/da ve olduğunu belirtmiştir. Ayrıca genotipler arasında verim farklılığına dikkat çekmişlerdir. Tarafimızdan elde edilen verim değerleri geniş bir aralıkta yer alırken incelenen birçok yerel genotipin verim değerlerinin yetiştiricilikte kullanılan çeşitlerden çok daha yüksek verim değerine sahip olması bu genotiplerin çeşit ıslahında doğrudan veya genitör olarak kullanılabilme potansiyelinin yüksek olduğunu göstermektedir.

Pazı populasyonlarının agromorfolojik özellikler yönünden değerlendirilmesine yönelik çalışma sayısı oldukça sınırlı iken yapılan çalışmalarda; genetik çeşitliliğin sadece agromorfolojik özellikler yönünden değil aynı zamanda mineral madde konsantrasyonu ve besin içeriği yönünden de yüksek olduğu vurgulanmaktadır. Genellikle populasyonların genetik özelliklerinin farklı olmasıyla açıklanabilen genetik çeşitlilik, kültürü yapılan türlerin uzun yıllar süresince yetiştirildiği bölgenin ekolojik ve edafik koşullarına adaptasyonu ile de oluşmaktadır. Çeşitler arasında besin kompozisyonu için gözlenen varyabilite özellikle hibrit ve yabani çeşitleri arasında yüksek iken ayrıca, beyaz ve kırmızı kök pazı çeşitleri içindeki $\mathrm{C}$ vitamini konsantrasyonu ve fenolik bileşikler arasında çeşitler yönünden farkl111klar bildirilmektedir (Rozycki ve ark., 1997; Gil ve ark., 1998; Pyo ve ark., 2004). Bozokalfa ve ark. (2016) uzun süreli ekim denemelerinde bile pazının genetik çeşitliliğinin dağılımı veya bu dağılımın agromorfolojik çeşitlilikle ilişkisi hakkında somut bir karara varmanın güç olduğunu belirtmiş ve pazı genotipleri arasında yüksek varyabiliteyi vurgulamıştır.

$\mathrm{Bu}$ çalışmada incelenen farklı coğrafi lokasyonlara ait genotiplerin agronomik özelliklerinde geniş varyasyon gözlemlenmiştir. Yaprak ağırlığı, yaprak sapı genişliği, yaprak sapı kalınlığı, yaprak uzunluğu, yaprak sapı uzunluğu ve yaprak genişliği incelenen bitki özellikleri arasında en ayırt edici karakterler olduğu belirlenmiştir. Frese (1991) Beta grubunda yer alan yaprağı tüketilen populasyonları incelemiş temel bileşen analizi sonucunda yaprak rengi yönünden aksesyonlar arasında farklıklar bulunduğunu bildirmiş ayrıca yaprak uzunluğu, yaprak genişliği, petiol uzunluğu ve genişliği gibi özelliklerin aksesyonların gruplandırılmasında kullanılabileceğini bildirmektedir.

Araştırmaya konu olan pazı aksesyonları ile yürütülen bir diğer çalışmada aksesyonlar besin içerikleri yönünden incelenmiş ve incelenen besin elementleri miktarları bakımından aksesyonlar arasında büyük farklılıklar belirlenmiştir (Bozokalfa ve ark., 2011). Ayrıca pazı çeşitleri arasında C vitamini yönünden (Gil ve ark., 1998), Pyo ve ark. (2004) ise antioksidan ve toplam fenol içeriği yönünden kırmızı ve beyaz gövde rengine sahip genotipler arasında varyabilite görüldüğünü bildirmektedir.

Pazı ülkemizde uzun yıllardır tüketilen, günümüzde ise sağlı̆ga yararlı bileşikler bulundurması, yüksek vitamin ve mineral içeriği ve düşük kalorili bir besin olması nedeniyle dünyada popülerliği her geçen gün artan olan bir sebzedir. Türkiye'de de pazı üretimi son yıllarda artış göstermektedir. İklim ve toprak isteği yönünden fazla seçici olmaması, uygun ekolojilerde uzun vejetasyon süresince hasat edilebilmesi nedeniyle yetiştiriciliği tercih edilmektedir. Diğer yandan hastalık ve zararlılara dirençli genlere sahip olması, türler arası melezlemeye imkan vermesi ve içerdiği önemli besin bileşikleri nedeniyle 1slah programları için değerli bir bitkidir. Uzun yıllardan beri yetiştirilen yerel populasyonların en büyük avantajı yetiştirildiği bölgenin koşullarına adapte olması ve bu özelliğini koruyabilmesidir. Bu bağlamda farklı bölgelere ve ekolojilere adapte olmuş yerel populasyonların islah programlarındaki önemi her geçen gün artmaktadır (Binici ve Bozokalfa, 2020). Dünya'da kültürü yapılan birçok türde yerel populasyonlar toplanarak ıslah materyali olarak kullanılmaktadır. 
$\mathrm{Bu}$ çalışmada kullanılan yerel pazı genotiplerinin belirlenen agronomik özellikleri incelendiğinde bazı parametrelerde ticari çeşitlerden üstün nitelikler gösterdiği veya farklı karakterlere sahip oldukları görülmüştür. Pazıda verimi oluşturan başlıca iki agronomik parametre yaprak ağırlığı ve bitki başına yaprak sayısı incelendiğinde genotipler arasında istatistiksel düzeyde ciddi farklılıklar olduğu gözlemlenmiştir. Yüksek verim komponentleri göz önünde bulundurulduğunda; yaprak ağırlığı yönünden TR 35354 ve TR 51170 genotipleri, bitki başına yaprak sayısı olarak incelendiğinde ise TR 55866, TR 55821 ve TR 55832 genotipleri umutvar olarak değerlendirilebilir. Ayrıca verim bazında ciddi farklar olduğu gözlemlenmiş özellikle TR 51170, TR 51154 ve TR 55821 genotiplerinin yüksek verim değerlerine sahip olduğu görülmüştür.

\section{Kaynakça}

Baranski, R., Grzebelus, D., \& Frese, L. (2001). Estimation of genetic diversity in a collection of the Garden Beet Group. Euphytica, 122, 19-29.

Binici, A. B., \& Bozokalfa M. K. (2020). Yerel Börülce (Vigna unguiculata (L.) Walp.) Populasyonlarının Bakla ve Danelerinin Agronomik Özelliklerinin Belirlenmesi. Ege Üniversitesi Ziraat Fakültesi Dergisi, Özel Sayı, 51-60.

Bozokalfa, M. K., Yağmur, B., Aşçıŏul, T. K., \& Eşiyok, D. (2011). Diversity in nutritional composition of Swiss chard (Beta vulgaris subsp. L. var. cicla) accessions revealed by multivariate analysis. Plant Genetic Resources, 9(4), 557-566.

Bozokalfa, M. K., Eşiyok, D., \& Aşçığul, T. K. (2016). Diversity pattern among agromorphological traits of the Swiss chard (Beta vulgaris L. subsp. vulgaris) genetic resources of Turkey. Turkish Journal of Agriculture and Forestry, 40(5), 684-695.

Cheng, D., Yoshida, Y., Kitazaki, K., Negoro, S., Takahashi, H., Xu, D., \& Kubo, T. (2011). Mitochondrial genome diversity in Beta vulgaris L. ssp. vulgaris (Leaf and Garden Beet Groups) and its implications concerning the dissemination of the crop. Genetic Resources and Crop Evolution, 58(4), 553-560.

Eşiyok, D., Bozokalfa, K. M., \& Kaygisiz-Aşçioğul, T. (2011). Variability, heritability and association analysis in plant traits of swiss chard (Beta vulgaris subsp. cicla). Genetika, 43(2), 239-252.

Frese L., Desprez B., \& Ziegler D. (2001). Potential of genetic resources and breeding strategies for base-broadening Beta. In: Broadening the Genetic Base of Crop Production. Wallingford (Eds: H.D. Cooper, C. Spillane and C, Hodgkin), UK, CABI Pub. pp. 295-309.

Gaskill, J. O. (1954). Viable hybrids from matings of chard with Beta procumbens and B. webbiana. American Society of Sugar Beet Technologist, 8, 5.

Gil M. I., \& Tomas-Barberan F. A. (1998). Effect of modified atmosphere packaging on the flavonoids and vitamin C content of minimally processed Swiss chard (Beta vulgaris ssp. cicla L.). Journal of Agriculture and Food Chemistry, 46, 2007-2012.

Goldman I. L., \& Navazio J. P. (2003). History and breeding of table beet in the United States. Plant Breeding Review, 22, 357-388.

Gürsul, H. (2015). Yabani pancar (Beta maritima L. var. pilosa Del.) bitkisinin sekonder metaboliklerinin yap tayini ve antioksidan aktivitelerinin belirlenmesi (Doktora Tezi), İstanbul Üniversitesi, İstanbul.

Lange, W., Brandenburg, W. A., \& De Bock, T. S. (1999). Taxonomy and cultonomy of beet (Beta vulgaris L.). Botanical Journal of the Linnean Society, 130(1), 81-96.

Letschert, J. W., Lange, W., Frese, L., \& Van Den Berg, R. G. (1994). Taxonomy of Beta section Beta. Journal of Sugar Beet Research, 31(1-2), 69-85.

Oyen, L. P. A. (2004). Vegetables Beta vulgaris L. In: Plant Resources of Tropical Africa 2. Vegetables, PROTA Foundation, In Grubben G. J. H. and O. A. Denton (Eds.), Backhuys Publishers, Lieden, Netherlands CTA (pp 110-113), Wageningen, Netherlands.

Pokluda, R., \& Kuben J. (2002). Comparison of selected Swiss chard (Beta vulgaris ssp. L cicla) varieties. Horticultural Science, 29, 114-118.

Pyo, Y. H., Lee, T. C., Logendra, L., \& Rosen, R. T. (2004). Antioxidant activity and phenolic compounds of Swiss chard (Beta vulgaris subspecies cycla) extracts. Food Chemistry, 85(1), $19-26$. 
Rozycki, V. R., Baigorria, C. M., Freyre, M. R., Bernard, C. M., Zannier, M. S., \& Charpentier, M. (1997). Nutrient content in vegetable species from the Argentine Chaco. Archivos Latinoamericanos de Nutricion, 47(3), 265-270.

Shen, Y., Ford-lloyd, B. V., \& Newbury, H. J. (1998). Genetic relationships within the genus Beta determined using both PCR-based marker and DNA sequencing techniques. Heredity, 80(5), 624-632.

Sun, Y. C. (1994). Beta germplasm collection and its application status in China, In: International Beta Genetic Resources Network. A Report on the 3rd International Beta Genetic Resources Workshop and World Beta Network Conference, In Frese L. and D.L. Doney (Eds.), North Dakota State University, Fargo, USA, 4-6 August 1994. International Crop Network Series 11. International Plant Genetic Resources Institute, Rome, pp 27-29.

Vural, H., Eşiyok, D., \& Duman İ. (2000). Kültür Sebzeleri (Sebze Yetiştirme), Ege Üniversitesi Basımevi, İzmir.

Yildırıml, Ş. (2003). The chorology of the Turkish species of Chenopodiaceae, Cistaceae, Convolvulaceae, Cornaceae and Corylaceae families. The Herb Journal Systematic Botanic, 10, 203-15. 